\title{
NCOA3 identified as a new candidate to explain autosomal dominant progressive hearing loss
}

\author{
R. Salazar-Silva ${ }^{1, \dagger}$, Vitor Lima Goes Dantas ${ }^{1}$, Leandro Ucela Alves ${ }^{1}$, \\ Ana Carla Batissoco ${ }^{1,2}$, Jeanne Oiticica ${ }^{2}$, Elizabeth A Lawrence ${ }^{3}$, \\ Abdelwahab Kawafi ${ }^{3}$, Yushi Yang ${ }^{4,5,6}$, Fernanda Stávale Nicastro ${ }^{7}$, \\ Beatriz Caiuby Novaes ${ }^{7}$, Chrissy Hammond ${ }^{3}$, Erika Kague ${ }^{1,3, \neq, *}$ and \\ R.C. Mingroni-Netto ${ }^{1, \neq}, *$
}

${ }^{1}$ Centro de Pesquisas sobre o Genoma Humano e Células-Tronco, Departamento de Genética e Biologia Evolutiva, Instituto de Biociências, Universidade de São Paulo, 05508-090, São Paulo, Brazil, ${ }^{2}$ Laboratório de Otorrinolaringologia/LIM32 -Hospital das Clínicas, Faculdade de Medicina, Universidade de São Paulo , 01246-903, São Paulo, Brazil, ${ }^{3}$ School of Pharmacology, Physiology and Neuroscience, University of Bristol, Bristol, BS8 1TD, United Kingdom, ${ }^{4}$ School of Physics, University of Bristol, Bristol, BS8 1TL, United Kingdom, ${ }^{5}$ Centre for Nanoscience and Quantum Information, University of Bristol, Bristol, BS8 1FD, United Kingdom, ${ }^{6}$ Bristol Centre for Functional Nanomaterials, University of Bristol, Bristol, BS8 1FD, United Kingdom and ${ }^{7}$ Divisão de Educação e Reabilitação dos Distúrbios da Comunicação da Pontifícia Universidade Católica de São Paulo, 04022-040, São Paulo, Brazil

*Corresponding authors: Regina Célia Mingroni Netto (renetto@ib. usp.br) and Erika Kague (erika.kague@bristol.ac.uk)

\begin{abstract}
Hearing loss is a frequent sensory impairment in humans and genetic factors account for an elevated fraction of the cases. We have investigated a large family of five generations, with 15 reported individuals presenting non-syndromic, sensorineural, bilateral and progressive hearing loss, segregating as an autosomal dominant condition. Linkage analysis, using SNP-array and selected microsatellites, identified a region of near $13 \mathrm{cM}$ in chromosome 20 as the best candidate to harbour the causative mutation. After exome sequencing and filtering of variants, only one predicted deleterious variant in the NCOA3 gene (NM_181659, c.2810C > G; p.Ser937Cys) fit in with our linkage data. RT-PCR, immunostaining and in situ hybridization showed expression of ncoa3 in the inner ear of mice and zebrafish. We generated a stable homozygous zebrafish mutant line using the CRISPR/Cas9 system. ncoa3-/- did not display any major morphological abnormalities in the ear, however, anterior macular hair cells showed altered orientation. Surprisingly, chondrocytes forming the ear cartilage showed abnormal behaviour in ncoa3-/-, detaching from their location, invading the ear canal and blocking the cristae. Adult mutants displayed accumulation of denser material wrapping the otoliths of ncoa3-/- and increased bone mineral density. Altered zebrafish swimming behaviour corroborates a potential role of ncoa3 in hearing loss. In conclusion, we
\end{abstract}

${ }^{\dagger}$ R. Salazar-Silva, http://orcid.org/0000-0001-7379-2115

†joint senior authors

Received: May 31, 2020. Revised: September 21, 2020. Accepted: October 15, 2020

(c) The Author(s) 2020. Published by Oxford University Press.

This is an Open Access article distributed under the terms of the Creative Commons Attribution License (http://creativecommons.org/licenses/by/4.0/), which permits unrestricted reuse, distribution, and reproduction in any medium, provided the original work is properly cited. 
identified a potential candidate gene to explain hereditary hearing loss, and our functional analyses suggest subtle and abnormal skeletal behaviour as mechanisms involved in the pathogenesis of progressive sensory function impairment.

\section{Introduction}

Hearing loss affects almost 466 million people worldwide and is estimated to affect more than 900 million people by 2050 (1). Genetic factors play an important role in the pathogenesis of the disease, with up to $55 \%$ of age-related hearing loss attributed to genetics (2). Approximately $70 \%$ of hereditary deafness cases are non-syndromic (3), of which $20 \%$ are autosomal dominant (2). Autosomal dominant non-syndromic hearing loss (ADNSHL) is typically progressive with late and variable average age of onset, which depends on the nature of the type of mutation and affected gene.

Mapping studies of large families have contributed to the identification of several genes associated with hearing loss (4). Recently, whole-genome and exome sequencing, in combination with familial cases, have boosted the identification of causal genes (4-8). The genetic complexity of the condition is highlighted by the large number of genes identified as associated to monogenic inheritance of non-syndromic hearing loss $(\sim 130)$, and among these, near 50 were related to ADNSHL (9). New genes are still to be identified, however, given the extensive genetic heterogeneity underpinning the origin of hearing loss, newly identified genes and variants are rarely found, in only one or a few pedigrees, making their confirmation by reproducibility a challenging task. Therefore, functional studies are key to validate the genetic findings.

Hearing loss associated genes fall into common categories such as maintenance of ionic homeostasis, formation of hair cell stereocilia and regulation of gene transcription (10-15). Recently, other pathways have also been suggested to play a role in disease pathogenesis; such as collagen biogenesis and homeostasis (1618). Thus, the identification of novel candidate genes associated with hearing loss could reveal new molecular players involved in the condition and potential therapeutics.

Here, we describe a large Brazilian family in which hearing loss segregates as an autosomal dominant trait. By linkage analysis and exome sequencing we identified a rare missense variant in the gene NCOA3 (NM_181659:c.2810C > G:p.Ser937Cys) that segregated in the pedigree with hearing loss. We detected expression of the gene in mice and zebrafish ears. Using CRISPR/Cas9 genome editing, we generated a zebrafish ncoa3-/which showed cartilage behaviour abnormalities in the larval sensorial region of the ear, amorphous material accumulation in proximity with adult otoliths, higher mineral density and abnormal adult swimming behaviour. Our work provides evidence of NCOA3 playing an important role in skeletal system homeostasis and suggests NCOA3 as a potential candidate gene associated with hearing impairment.

\section{Results}

Clinical findings in patients of a family with autosomal dominant, non-syndromic, sensorineural hearing loss

The five-generation Brazilian family examined in this study presented individuals affected by non-syndromic, progressive, sensorineural, bilateral, moderate-to-profound hearing loss, segregating as an autosomal dominant condition (Figure 1A). Affected and non-affected individuals were submitted to audiological tests (Figure 1B). Age of onset of hearing loss varied from 4 to 35 years, with the average age of onset being 12 years old (Table 1).

We performed ear, nose and throat (ENT) physical examinations. Patients III-5, III-8, III-10, IV-20 and IV-21, showed normal results, as well as normal computed tomography scan of temporal bones, magnetic resonance imaging of the inner ear and thyroid ultrasound. IV-20 and IV-21 had bilateral mild earlobe hypogenesis. IV-21 showed coloboma auris. Other minor clinical findings were also observed. IV-5, IV-6: bifid uvula at oropharynx cavity examination; III-8 and III-10: normal responses from the otoneurological evaluation, including electrooculography with caloric tests; and III-5: despite the absence of vestibular complaints, showed right idiopathic vestibular weakness on caloric test.

\section{Linkage analysis points to a region of $13.5 \mathrm{Mb}$ on chromosome 20}

LOD score values were obtained from a $50 \mathrm{~K}$ SNP-array analysis. LOD scores were calculated from filtered SNP array dataset, after excluding markers with linkage disequilibrium. A total of 9800 SNPs was used in calculations, assuming both complete $(\mathrm{K}=1)$ and incomplete $(\mathrm{K}=0.9, \mathrm{~K}=0.8, \mathrm{~K}=0.64$, and $\mathrm{K}=0.4)$ penetrance. LOD scores calculations suggested linkage to chromosome 20 (chr20:38982828-51730894, 66.4 and $87.8 \mathrm{cM}$, GRCh37/hg19), with maximum positive value of $1.794(\mathrm{~K}=1), 1.793(\mathrm{~K}=0.9)$, $1.792(\mathrm{~K}=0.8), 1.789(\mathrm{~K}=0.64)$ and $1.780(\mathrm{~K}=0.4)$. This region has $12,75 \mathrm{Mb}$ (Figure 1D). No other chromosomal region showed higher LOD scores than the ones obtained in chromosome 20.

We selected twelve microsatellite markers mapped along chromosome 20 (Supplementary Figure 1, Supplementary Table 1), which confirmed our SNP-array analysis pointing to a candidate region between 58 and $79 \mathrm{cM}$ (complete penetrance, $\mathrm{K}=1$, maximum LOD score $=1.006$ ) and between 56 and $83 \mathrm{cM}$ (incomplete penetrance, $\mathrm{K}=0.8$ and $\mathrm{K}=0.64$, maximum Lod score $=1.822$ ). The maximum two-point LOD score value for this pedigree was simulated for complete $(k=1)$ and incomplete $(\mathrm{K}=0.8$ and $\mathrm{K}=0,64)$ penetrance resulting in $4.214,3.580$ and 3.145 , respectively.

\section{Variant in NCOA3 identified as candidate for hearing loss by whole-exome sequencing}

We conducted whole-exome sequencing in samples from two of the affected individuals (III- 8 and III-10) (Figure 1A); obtaining approximately $70 \mathrm{M}$ reads per sample (read average length of $99 \mathrm{bp}$, average coverage of $120 \mathrm{X}$ and $98 \%$ of target bases with more than 20 reads). We selected autosomal, exonic, heterozygous and nonsynonymous variants with $Q>30$ and coverage $>20$, checked them against public variant databases and 66 control samples (sequenced simultaneously), and filtered for variants with frequencies lower than 0.01. A total of 162 variants shared by both samples were obtained (Table 2; Supplementary Table 2). From these variants, only the NM_181659: c.2810C > G: p.S937C in NCOA3 gene matched the suggestive positive LOD score region mapped in the chromosome 20 , as indicated by the linkage analysis. 


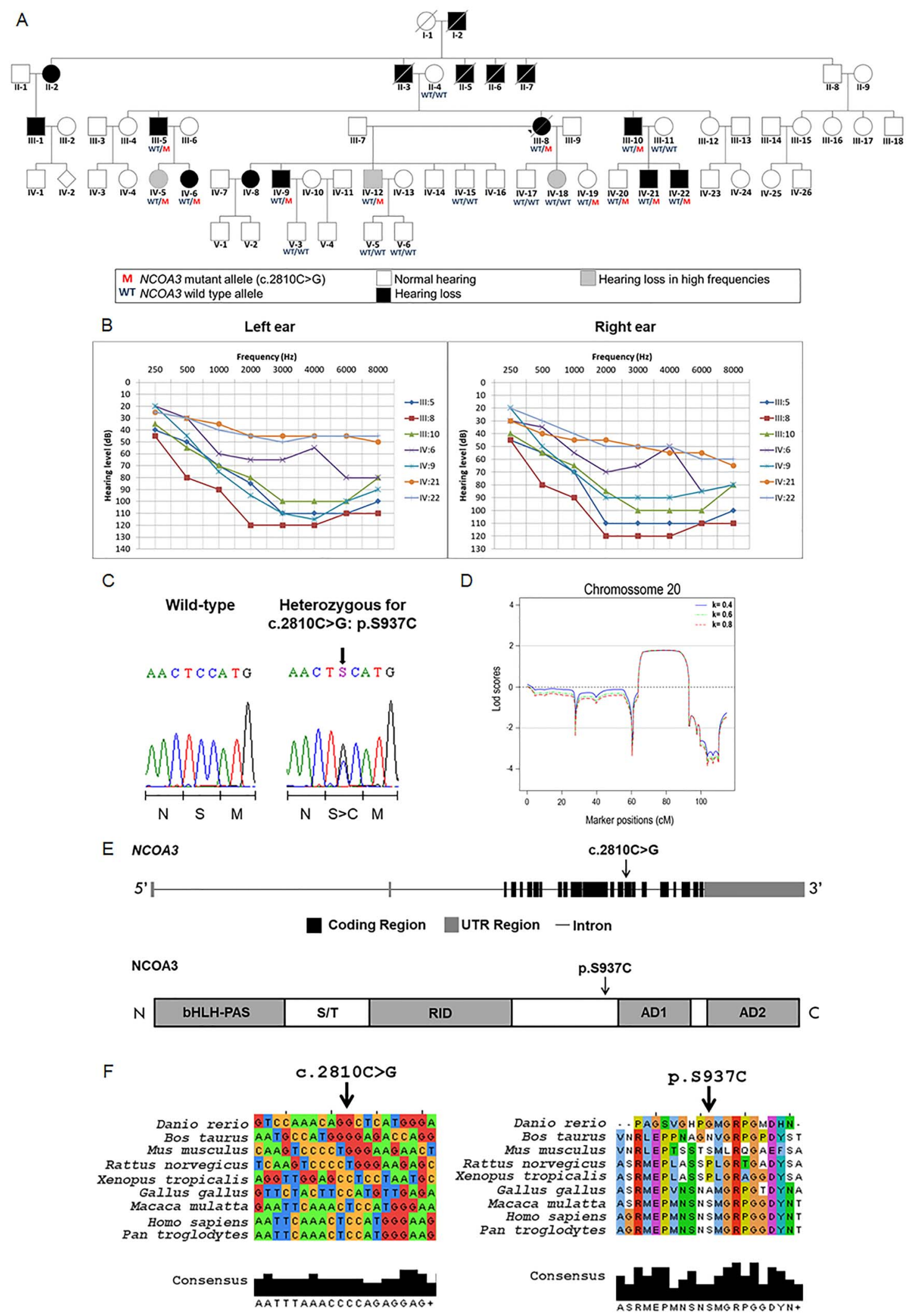

Figure 1. A rare variant in NCOA3, a gene which codes a nuclear receptor coactivator, segregates with hearing loss in the family. A) Pedigree showing the segregation of the NCOA3 variant (NM_181659: c.2810C > G: p.Ser937Cys). B) 14 audiometric profiles (divided in right and left ear) of 7 patients affected with sensorineural and bilateral hearing loss. Hearing thresholds until $20 \mathrm{~dB}$ are considered normal. C) Chromatograms showing partial sequence from affected patient compared to a wild-type sequence. Arrow indicates position of the NCOA3 variant, while scale bar below indicates which amino acid is changed when the variant is present. D) Multipoint LOD scores calculated with Merlin software for chromosome 20 , using data from SNP arrays, under assumption of penetrance $\mathrm{K}=0.4, \mathrm{~K}=0.6$ and $\mathrm{K}=0.8$. 
Table 1. Reported ages of onset for hearing loss and ages at the time of clinical examination

\begin{tabular}{|c|c|c|c|c|}
\hline Patient ID & Classification & Severity of hearing loss & Age at examination (years) & Age of onset (years) \\
\hline III-5 & Affected & $\begin{array}{l}\text { Moderate in right ear and } \\
\text { severe in the left ear }\end{array}$ & 48 & 8 \\
\hline III-8 & Affected & Profound & 40 & 35 \\
\hline III-10 & Affected & Moderate & 45 & 20 \\
\hline IV-6 & Affected & Mild & 24 & 7 \\
\hline IV-9 & Affected & Mild to severe & 22 & 6 \\
\hline IV-21 & Affected & $\begin{array}{l}\text { Moderate in right ear and } \\
\text { mild in left ear }\end{array}$ & 8 & 6 \\
\hline IV-22 & Affected & Mild & 4 & 4 \\
\hline II-4 & Not affected & - & - & - \\
\hline IV-5 & Not affected & Threshold of $35 \mathrm{~dB}$ only at $6 \mathrm{~K}$ & 27 & - \\
\hline IV-12 & Not affected & Threshold of $30 \mathrm{~dB}$ only at $6 \mathrm{~K}$ & 26 & - \\
\hline IV-15 & Not affected & - & 20 & - \\
\hline IV-17 & Not affected & - & 15 & - \\
\hline IV-18 & Not affected & Threshold of $28 \mathrm{~dB}$ only at $6 \mathrm{~K}$ & 11 & - \\
\hline IV-19 & Not affected & - & 8 & - \\
\hline IV-20 & Not affected & - & 11 & - \\
\hline $\mathrm{V}-3$ & Not affected & - & 3 & - \\
\hline$V-5$ & Not affected & - & 5 & - \\
\hline V-6 & Not affected & - & 4 & - \\
\hline
\end{tabular}

Table 2. Steps of variant filtering after exome sequencing of samples from two affected individuals. ${ }^{*}=66$ control samples that were sequenced in the same batch. ${ }^{* *}=1000$ genomes, NHLBI Exome Sequencing Project, Online Archive of Brazilian Mutations databases

\begin{tabular}{ll}
\hline Filtration steps of exonic variants & $\begin{array}{l}\text { \# of remaining } \\
\text { variants }\end{array}$ \\
\hline $\begin{array}{l}\text { Heterozygous variants found in both patients } \\
\text { analysed }\end{array}$ & 9197 \\
$\begin{array}{l}\text { Exclusion of low-quality variants } \\
\text { Exclusion of variants with } \mathrm{f}>1 \% \text { in }\end{array}$ & 9193 \\
$\begin{array}{l}\text { control-samples* } \\
\text { Exclusion of variants with } \mathrm{f}>1 \% \text { in }\end{array}$ & 553 \\
$\begin{array}{l}\text { databases** } \\
\text { Considering only variants in autosomes }\end{array}$ & 350 \\
$\begin{array}{l}\text { Exclusion of variants in hypervariable genes } \\
\text { Exclusion of synonymous variants }\end{array}$ & 349 \\
$\begin{array}{l}\text { Considering only variants in chromosome 20 } \\
\text { Considering only variants in the positive Lod } \\
\text { score region }\end{array}$ & 162 \\
\hline
\end{tabular}

Only two variants were detected in genes previously described as associated to hearing loss: NM_001258370: c.A1565G -:p.Gln522Arg (DIAPH3) and NM_005709: c.G946C:p.Glu316Gln (USH1C). The variants in DIAPH3 and USH1C were investigated in the pedigree by Sanger sequencing, and their segregation was not compatible with the segregation of hearing loss in the family (Supplementary Figure 2). Moreover, copy-number variation was excluded after array-CGH (Agilent Technologies, $180 \mathrm{~K}$ ).

NCOA3 (Nuclear Receptor Coactivator 3) comprises 23 exons, encoding a protein of 1420 amino acids, with a suggested function in the regulation of gene transcription, mediated by nuclear receptors and it has never been reported to be associated with hearing loss. The variant c. $2810 \mathrm{C}>\mathrm{G}$ in exon 15 is predicted to result in a p.Ser937Cys amino acid substitution within a highly conserved region among primates (Figures $1 \mathrm{E}$ and F). This variant was predicted to be damaging using several prediction tools: SIFT showed a damaging score of 0.030 , and Polyphen2, a score of 0.905 . MutationTaster2 predicted that it is a diseasecausing mutation (score of 0.845). The variant, rs142951578, within NCOA3 has been reported with low frequency by GnomAD (0.0003465), NHLBI-ESP (0.000538), 1000 genomes (0.001) and was not described by ABraOM.

We investigated the segregation of NM_181659: c.2810C > G: p.Ser937Cys in NCOA3 by Sanger sequencing in 19 samples. This variant was found to be present in heterozygosis in all seven affected individuals and in 4 non-affected ones (Figure 1A and 1C). These four heterozygous non-affected individuals are within the range of onset of hearing loss observed in the family (4-35 years, Table 1 ), therefore, it is possible that manifestation of hearing loss will occur later.

\section{Ncoa3 is expressed in the developing mouse cochlea and zebrafish ear}

Ncoa3 expression in mice has been reported for ovary, testis, liver, skeletal muscle and adipose tissue (19-21), and transcriptome studies have suggested its expression in the ear $(22,23)$, however this has been poorly characterised. To determine the temporal pattern of Ncoa3 expression in the inner ear of mice we performed RT-PCR and immunofluorescence on histological sections for 3 distinctive developmental stages: P4, P10 and P16. Ncoa3 expression was detected in the cochlea and the organ of Corti with stria vascularis in all the time-points (Figure 2A and B). In addition to these structures, immunofluorescence showed cytoplasmic localisation of Ncoa3 in the Reissner membrane, basilar membrane, spiral limbus and spiral ganglion (Figure 2B).

E) Schematics of NCOA3 gene and its respective protein. bHLH = basic helix-loop-helix domain; PAS=Per/ARNT/Sim homologous domain; S/T = serine/threonine-rich region; RID = receptor interaction domain containing multiple LXXLL motifs; AD1 and AD2 = activation domains 1 and 2. F) Multiple alignment of NCOA3 gene and its orthologous (left), as well as multiple alignment of the respective proteins (right). Arrow indicates position of NCOA3 variant (NM_181659: c.2810C > G: p.Ser937Cys). 
Zebrafish have only one ortholog of NCOA3. Whole mount in situ hybridization in zebrafish showed ncoa3 expression in the otic vesicle of 3 and $5 \mathrm{dpf}$ zebrafish larvae (Figure 2C). Interestingly, there was continued expression even after the ear system is completely developed, as detected in the inner ear of juvenile fish (5 and 7wpf, weeks post fertilization) (Figure 2C). ncoa3 expression was not detected in neuromasts (mechanosensory system able to detect small water vibrations). Therefore, our results suggest a conserved expression pattern of Ncoa3 in the ear.

\section{Zebrafish ncoa $3^{\text {bi456/bi456 }}$ show cartilage cell behaviour abnormality in the otic vesicle.}

In order to investigate the potential role of NCOA3 in the pathogenesis of hearing impairment, we generated ncoa3 homozygous zebrafish mutants using CRISPR/Cas9 genome editing.

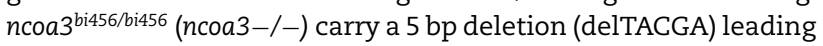
to a premature stop codon at position 518aa (S518_Y1520del), reducing the protein size from 1520aa to 517aa. Human and zebrafish sequence alignment showed conservation of 2 out of $5 \mathrm{bp}$ within the deletion site. A deleterious effect was predicted when simulating the same mutation in the human ortholog.

NCOA3 has been previously associated, through GWAS studies, with osteoarthritis, bone mass, abnormal cartilage behaviour, and notch signalling pathway (24-28). To investigate chondrocyte behaviour and sensory cells expressing notch in the zebrafish ear, we crossed ncoa $3^{\text {bi456/bi456 }}$ to a double transgenic line carrying Tg(col2:mcherry; notch:egfp). Zebrafish ncoa3 $3^{\text {bi456/bi456 }}$ did not display any major morphological abnormalities of the ear at 5dpf (Supplementary Figure 3A and B). Surprisingly, we detected abnormal clusters of cartilage cells (mcherry positive) lining the cristae region in $95 \%$ of larvae (Figure 3A). 3D image analysis showed tight association of abnormal cartilage cells with notch positive sensory cells (Figure 3A). To examine if detachment of cartilage cells from main cartilage elements (exostosis) was disrupting the hair cells, we measured the lengths of the stereocilia and cupula of the lateral and anterior cristae at $5 \mathrm{dpf}$ and no significant differences were detected (Supplementary Figure 3C).

In addition, phalloidin staining, which labels actin filaments of the stereocilia, was performed to evaluate stereocilia of other regions of the ear. Interestingly, we detected disorganised distribution of stereocilia of the macula (4/4 of ncoa3-/- and 0/3 wildtype (wt)) (Figure 3B). We investigated earlier stages of development (2-3dpf) to understand when chondrocytes were first misplaced. While at $2 \mathrm{dpf}$ no differences were detected, by $3 \mathrm{dpf}$ ectopic chondrocytes were observed at the cristae and internal regions of the ear canal (Supplementary Figure 4). This suggests exostosis of cartilage cells from the ear cartilage layer towards the cristae regions and internally. We did not detect changes in the neuromasts throughout the larvae, neither in the lateral line (data not shown). We also did not observe differences in larval swimming behaviour of ncoa3 $3^{\text {bi456/bi456 }}$ at $5 \mathrm{dpf}$ (data not shown). Our results suggest abnormal cartilage behaviour (exostosis) and disruption of stereocilia organisation in the macula as a potential progressive and subtle mechanism underlying hearing loss.

\section{Higher craniofacial bone density and ectopic mineralisation within the ear of ncoa $3^{\text {bi456/bi456 adult }}$ zebrafish}

Otoliths consist of a proteinaceous core that is biomineralized by calcium carbonate; in the adult fish ear, a single otolith is tethered to each of the utricular, saccular and lagenal sensory maculae allowing sensation of linear accelerations and sound (29). It has been shown that mutations in Otogelin and $\alpha$-Tectorin impair otolith seeding (30), and mutations in their human orthologs OTOG and TECTA cause deafness. Therefore, the shape and density of otoliths are indicative of possible defects in the hearing system. ncoa $3^{\text {bi456/bi456 }}$ survive to adulthood and are fertile. To analyse the 3D structure of the adult ears, we performed micro-computerised tomography $(\mu \mathrm{CT})$ of 1 year old mutants $(n=8)$ and wts $(n=25)$. We observed higher bone mineral density of craniofacial bones of $n \operatorname{coa}^{36456 / b i 456}$ and abnormal and disorganised mineralisation of amorphous material was detected in $75 \%(6 / 8)$ of the ears of ncoa $3^{b i 456 / b i 456}$, but was never observed in wt (Figure 4A). This mineralisation was attached to the lagenal otoliths, which is clearly observed through cross sections (Figure 4A, arrows). We did not deteect abnormalities in the utricular and saccular otoliths. Moreover, otoliths showed increased bone mineral density in mutants (Figure 4A and C). Therefore, these results suggest a role of ncoa 3 in bone and ectopic mineralisation regulation in the ears that could lead to progressive hearing impairment in adult fish.

It has been shown that vestibular function can be assessed through swimming behaviour analyses (31). Therefore, to test if the fish displayed any signs of hearing loss we analysed swimming behaviour by tracking individual fish in 2D in a tank containting a shaded corner, and calculating the spatial distribution heterogeneity of fish under constant ambient background noise. Vestibular malfunction has been associated to abnormal exploratory behaviour in zebrafish (31). We hypothesised that if hearing function is altered in $n c 0 a 3^{b i 456 / b i 456}$, these fish would display a distinct exploratory behaviour, dispersing from the shaded corner of the tank more often than the wt. While the wt $(n=7)$ was retained mostly to the shady corner, interestingly the $n$ coa3 $^{\text {bi456/bi456 }}(\mathrm{n}=6)$ showed increased spatial distribution heterogeneity, detected through the comparison of total trajectory distribution between both groups (Figure 5). Our results suggest possible hearing malfunctioning in ncoa $3^{\text {bi456/bi456 due to }}$ differences in bone densities, and ectopic mineral deposition.

\section{Discussion}

Non-syndromic hearing loss is a condition that affects almost 466 million people worldwide and is characterized by a broad heterogeneity of causes, among them genetic factors play an outstanding role (2). Reported genes and variants associated with monogenic forms of the disease have been identified from independent pedigrees and the rarity of some variants implies that some candidates are hardly reproducible. Therefore, functional studies are key to support genetic findings. In this sense, animal models such as mice and zebrafish are valuable and have proved relevant to the investigation of molecular mechanisms that underlie hearing loss in humans (30,32-34). The molecular and cellular mechanisms involved in ear development and homeostasis are highly conserved through evolution and zebrafish have been used elsewhere to study ear development and to confirm candidate genes involved in hearing loss (35-39).

Here, combining linkage analysis with exome sequencing and functional analysis we have reported for the first time an association between segregation of a rare variant in NCOA3 and hearing loss, suggesting a novel mechanism leading to the pathogenesis of hearing impairment. NCOA3 is a nuclear receptor coactivator from the NCOA gene family, positively regulating nuclear receptor-mediated gene transcription (40). We identified a missense variant in NCOA3, c.2810C > G: p.Ser937Cys, of which 
A $\begin{array}{ccccccc}\text { P16 } & \text { P16 } & \text { P10 } & \text { P10 } & \text { P4 } & \text { P4 } & \\ \text { Cochlea } & \text { Organ of Corti Cochlea } & \text { Organ of Corti } & \text { Cochlea } & \text { Organ of Corti } & \text { Water }\end{array}$

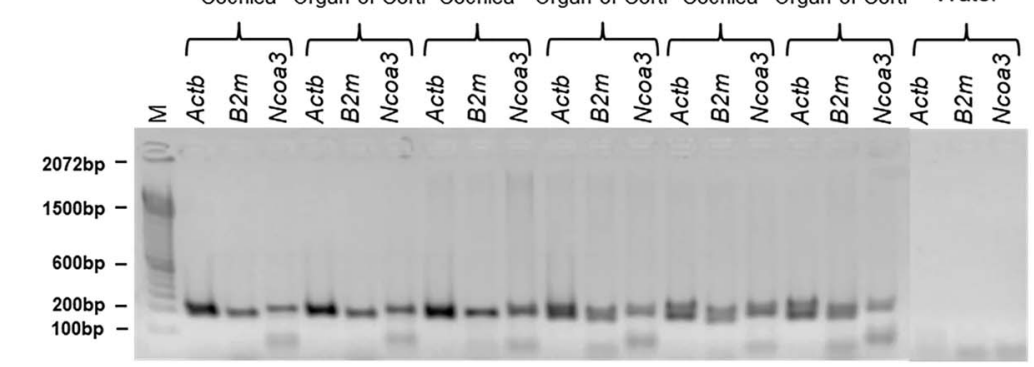

B
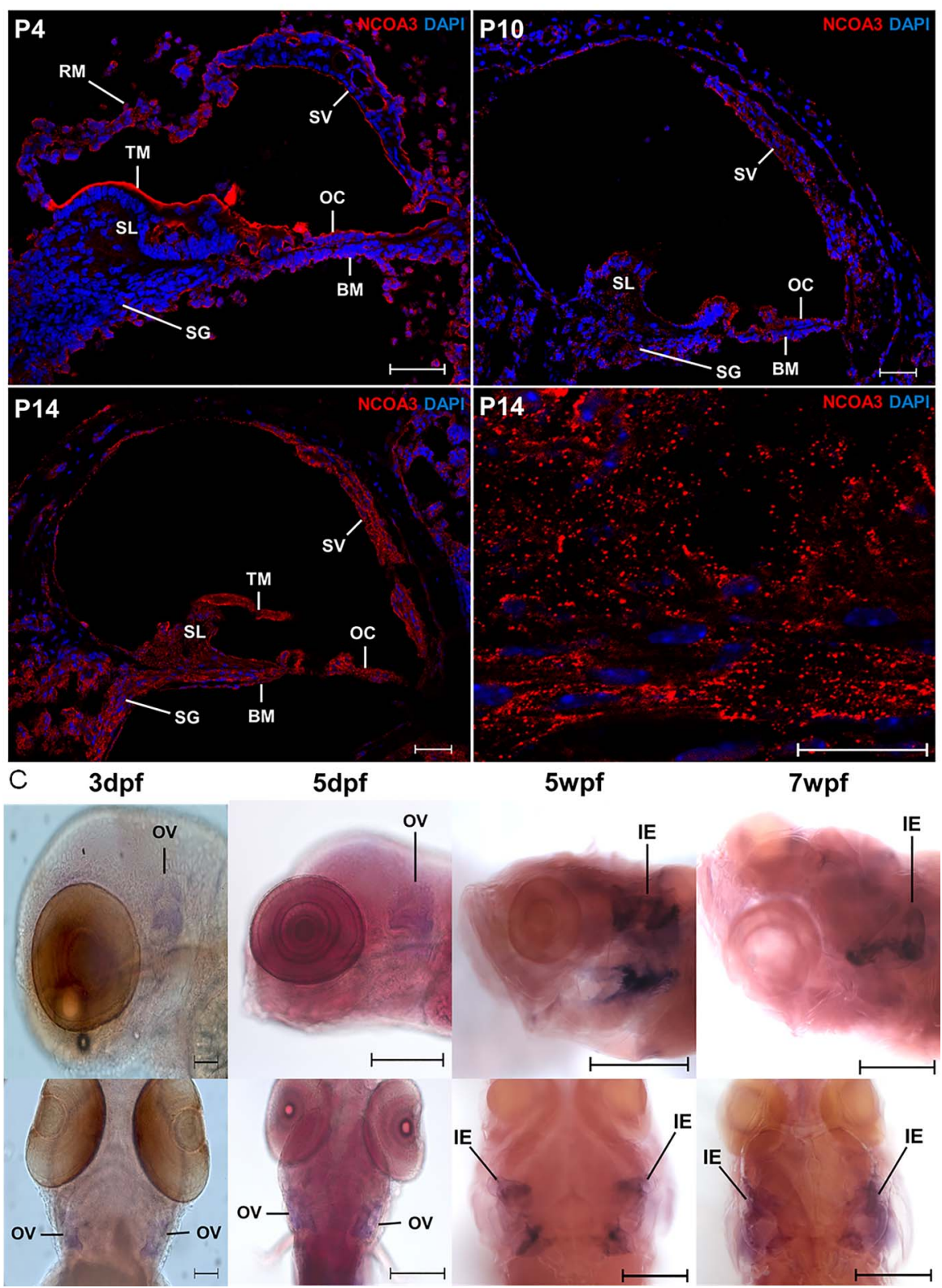

$5 \mathrm{wpf}$

7 wpf

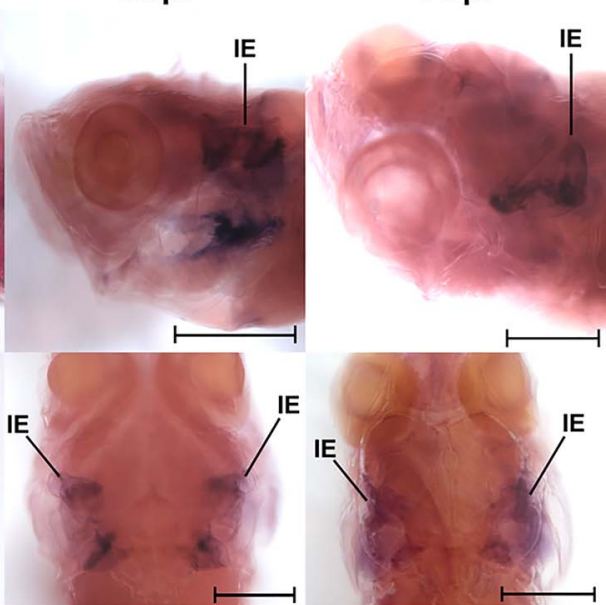

Figure 2. Ncoa3 is expressed in mice ear at P4, P10 and P16. A) RT-PCR shows expression of Ncoa3 and housekeeping genes Actb and B2m for the different stages of mice cochlea development and Organ of Corti. $\mathrm{M}=100 \mathrm{bp}$ molecular weight. Note that Ncoa3 is expressed in all stages analysed and in both tissue samples. B) Immunofluorescence on transversal histological sections of mice cochlea. In the bottom right corner, a greater zoom of P14 mice cochlea is displayed, showing expression pattern of NCOA3. Anti-NCOA3 (red) has been used, with nuclei shown in blue (DAPI). BM= Basilar Membrane, OC= Organ of Corti, RM = Reissner Membrane, SG=Spiral Ganglion, SL=Spiral Limbus, SV =Stria Vascularis, TM=Tectorial Membrane. C) Expression of endogenous ncoa3 in zebrafish inner ears at larval stages: 3 $\mathrm{dpf}$ and $5 \mathrm{dpf}$ (days post-fertilization); and juvenile stages: $5 \mathrm{wpf}$ and $7 \mathrm{wpf}$ (weeks-post-fertilization). OV= Otic Vesicle, IE= Inner Ear. Scale bars $=200 \mu \mathrm{m}$ for 3 and $5 \mathrm{dpf}$, and $500 \mu \mathrm{m}$ for 5 and $7 \mathrm{wpf}$. 
A
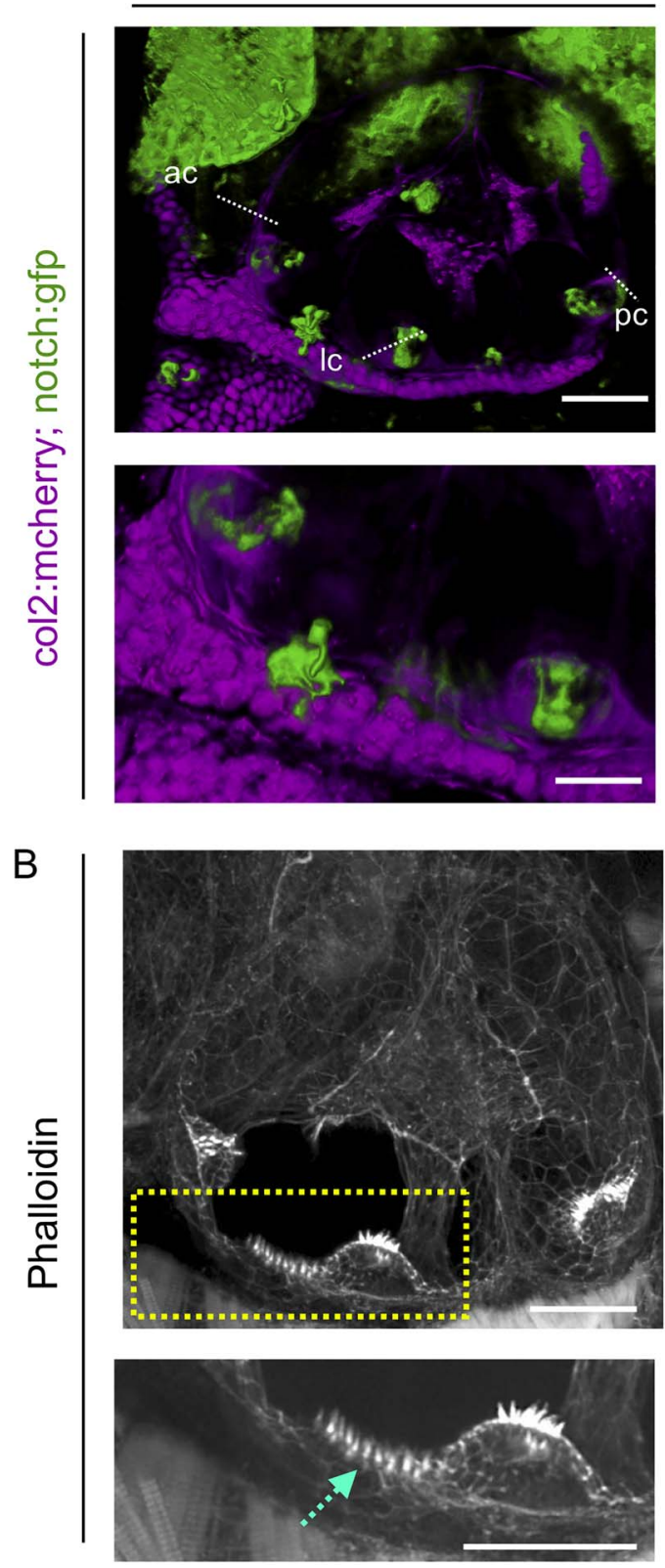

nсоа3-/-
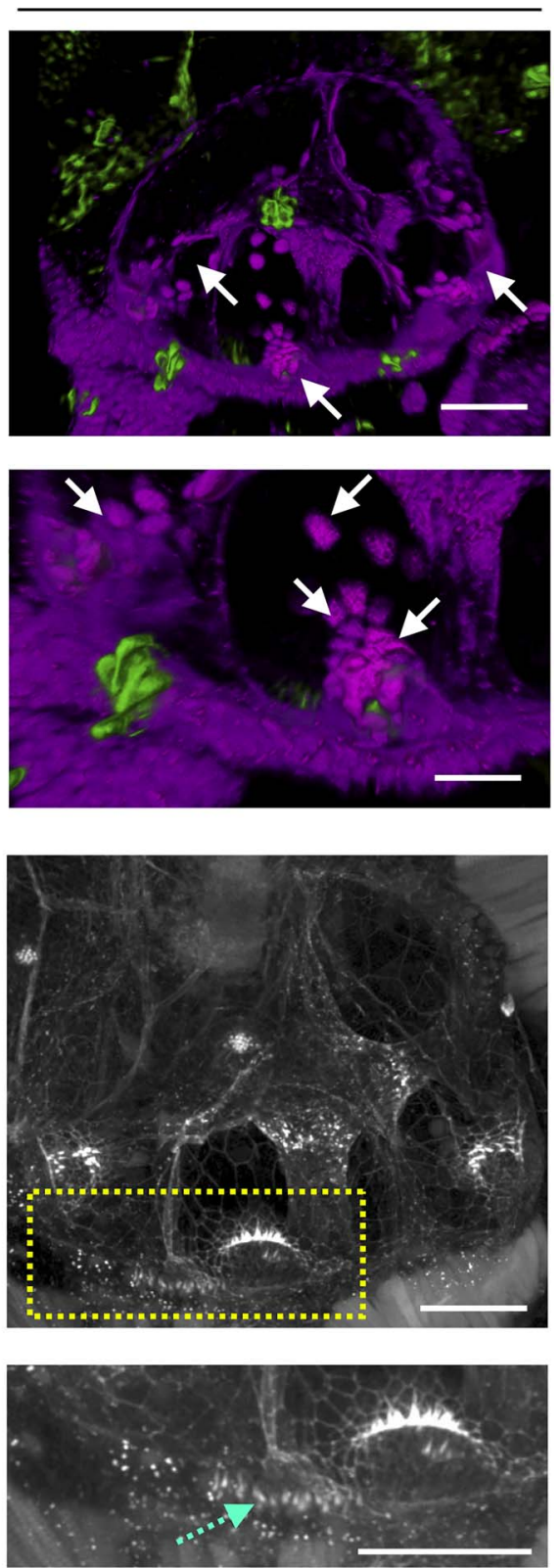

Figure 3. Abnormal cartilage behaviour and macula hair distribution in ears of ncoa3-/- A) 3D renders from confocal images of wt and ncoa3-/- carrying $\mathrm{Tg}(\mathrm{col2}:$ mcherry, notch:gfp) to show cartilage and cristae, respectively. Arrows indicate abnormal cartilage cell behaviour (cell exostosis). (ac $=$ anterior crista, lc = lateral crista, $\mathrm{pc}=$ posterior crista). Scale bars $=50 \mu \mathrm{m}$. Regions of anterior crista and macula were zoomed in. Scale bars $=20 \mu \mathrm{m}$. B) Phalloidin staining and confocal imaging to show the distribution of hair cells. Yellow dashed box to show zoomed in region. Abnormal distribution of hair cells was observed in the macula (dashed cyan arrows). Scale bars $=50 \mu \mathrm{m}$, zoomed in region $=20 \mu \mathrm{m}$.

computation predictions and frequency are compatible with the hypothesis of this variant being causative of hearing loss. We have provided further expression data in mice and zebrafish ears, that point to evolutionary conservation of gene function in the ear. Moreover, through CRISPR/Cas9 we have generated a ncoa3 zebrafish knockout to further investigate the effects of loss of function of ncoa 3 in the ear during development and ageing.

NCOA3 function has been linked to reproductive development and physiology regulation (41-44), pluripotency regulation (45), neurotransmitter metabolism regulation (46), adipogenesis promotion (47), long-chain fatty acid metabolism regulation (21).
In mice, although around $10 \%$ of the knockout animals for Ncoa3 exhibit a unilateral drop of the ear (48), they were not submitted to audiological evaluation. In a previous transcriptome analysis study of mice tissue, Ncoa3 expression has been reported in organ of Corti of E16, P0, P4 and P7 C57BL/6, with more pronounced expression levels observed in the postnatal phases (22). Transcriptome analysis of inner and outer hair cells from P25P30 CBA/J mice cochleae also indicated expression of Ncoa3 (23). Our results not only confirmed Ncoa3 expression in the organ of Corti of P4 mice, but also complemented the aforementioned studies, showing that the gene is still active in more advanced 
A
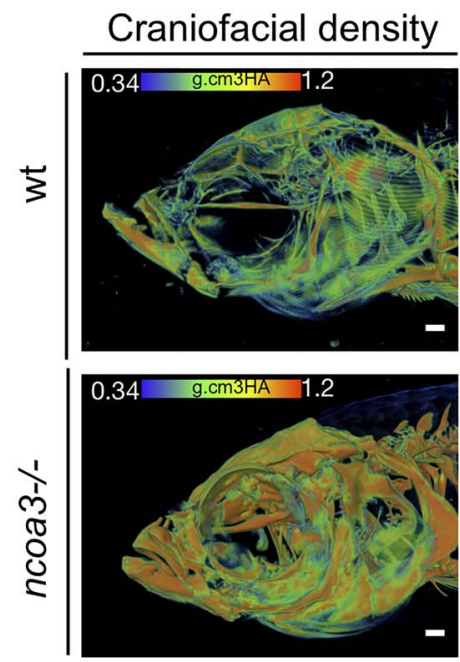
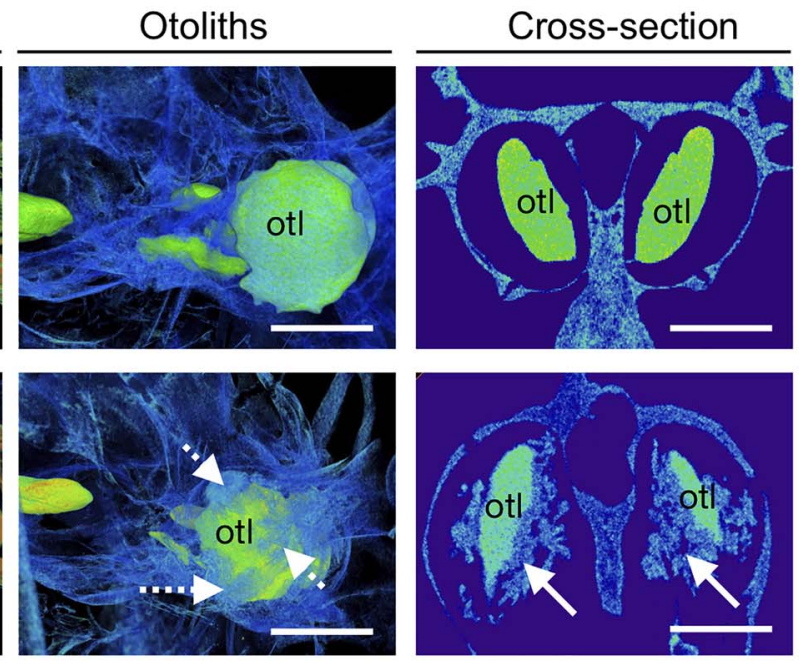

B

C
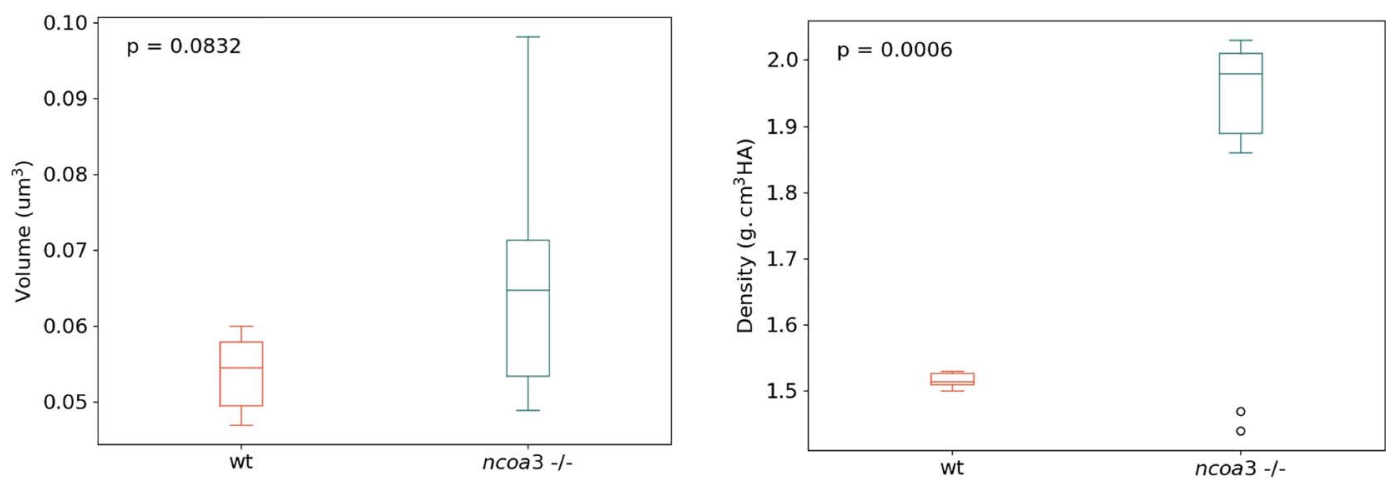

Figure 4. Abnormal mineralisation of amorphous material within the adult inner ears and higher BMD in $n$ coa3 $-/-$. A) $3 \mathrm{D}$ renders from $\mu \mathrm{CT}$ images of wt and $n c 0 a 3-/-$ of same age ( 1 year old). The head was color-coded to show bone mineral density ( $\mathrm{g} \cdot \mathrm{cm}^{3} \mathrm{HA}$; $\left.\min =0.338 ; \max =1.124\right)$. Note that craniofacial bones in ncoa3 mutants have higher density compared to wt. Otoliths (otl=arrows) were zoomed in. Abnormal mineralisation (dashed arrows) is observed attached to the otoliths. A cross section picture was taken to show the mineralised amorphous material (arrows) juxtaposed to the otoliths. B) Volume of otoliths. C) Bone mineral density of central region of otoliths. Non-parametric, two-tailed, independent Student's t-Test was used as statistical analysis $(p<0.05)$. Scale bars $=500 \mu \mathrm{m}$.

ages, near the end of cochlea maturation (P10 and P16). Moreover, we showed evidence of NCOA3 protein expression in the mice hearing system. Protein expression has been detected in all mice ages studied (P4, P10 and P14), with expression pattern spread along several cochlear structures: basilar membrane, Reissner membrane, organ of Corti, stria vascularis, spiral limbus and spiral ganglion. Altogether, our results suggest that Ncoa3 may have an important role in the development and physiology of mice auditory system.

We also detected expression of ncoa 3 in zebrafish during and after the completion of the inner ear development. In addition to the inner ear, fish have another component to their mechanosensory system; the lateral line, which is also formed by hair cells, supporting cells and sensory neurons, forming units called neuromasts which are key during the startle swim behaviour response $(49,50)$. Although there are genes that are expressed both in the inner ear and lateral line, such as atoh1a $(51,52)$ and $n g n 1(53)$ and that larval behaviour is observed when such genes are knocked out, ncoa3 does not follow this pattern, as we did not detect its expression in the neuromasts or changes to larval startle swim behaviour response in zebrafish ncoa3 ${ }^{\text {bi456/bi456. }}$.
Functional analysis carried in zebrafish $n$ coa $^{\text {bi456/bi456 }}$ showed that ncoa 3 is dispensable for development of the inner ear, but it is important for the maintenance the skeletal system. Although we did not detect morphological changes (size and shape of ear) in larval stages, abnormal cartilage cell behaviour was a

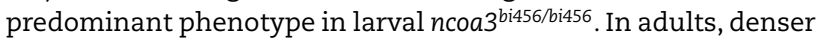
craniofacial bones and otoliths, and ectopic mineralisation in the ears were detected. Abnormal invading cartilage cells could potentially contribute to ectopic mineralisation in the vestibular region during ageing. Recent studies inferred NCOA3 involvement in maintaining skeletal homeostasis, with evidence of its function in bone mass (27), behaviour and molecular signature of chondrocytes $(54,55)$. Thus, sustaining its role in regulation of bone density and cartilage behaviour, respectively. Changes in bone mineral density have also been associated with hearing loss. Loss of bone mineral density in the cochlea capsule has been related to hearing loss in Paget's disease (osteoclast/bone resorption disorder (56). Mutations in SOST (sclerostosis and van Buchem's disease) cause enhanced bone formation, higher bone mineral density, and calvaria overgrowth, which frequently compresses cranial nerves leading to hearing loss (57). Although computed tomography scans of temporal bones revealed normal 
A

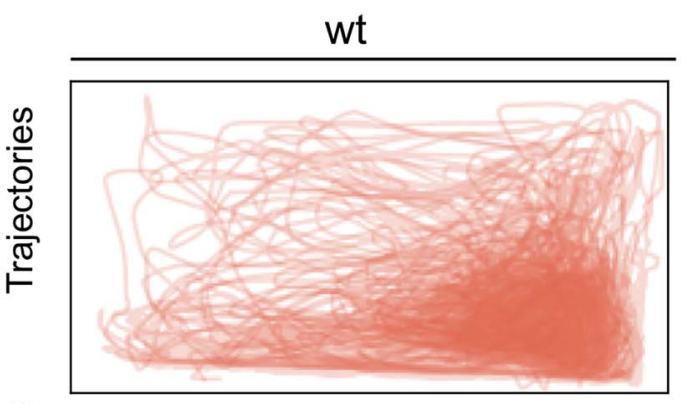

B

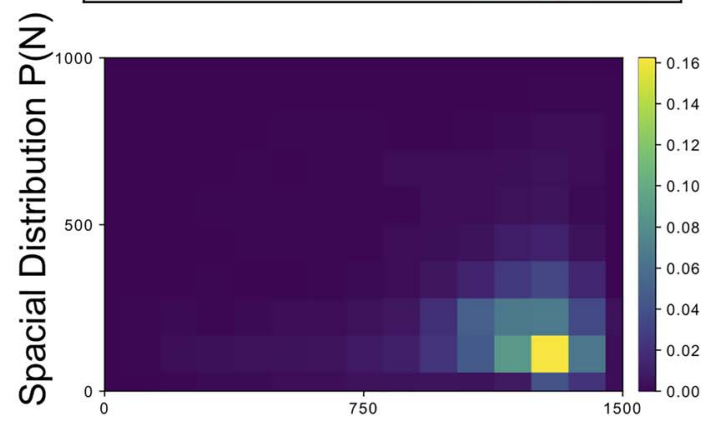

ncoa3-/-
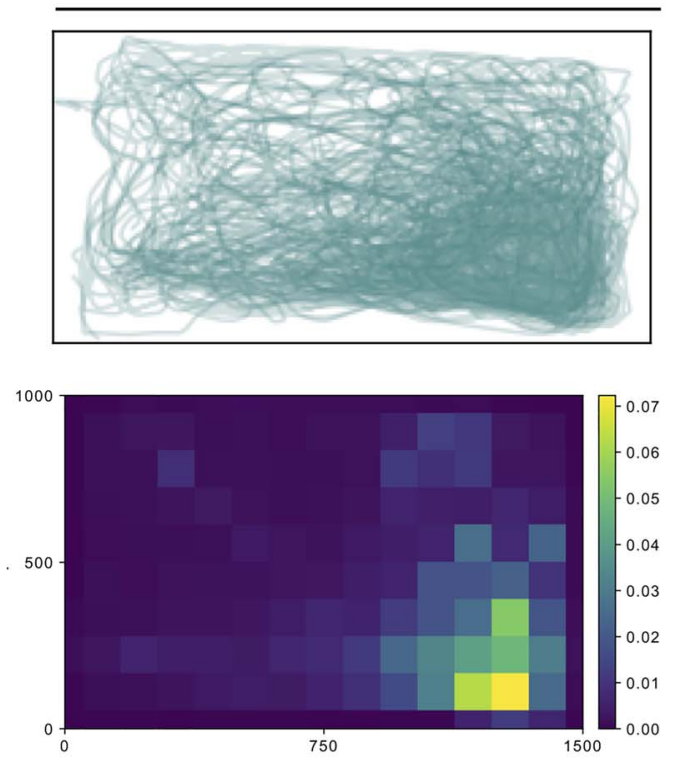

C

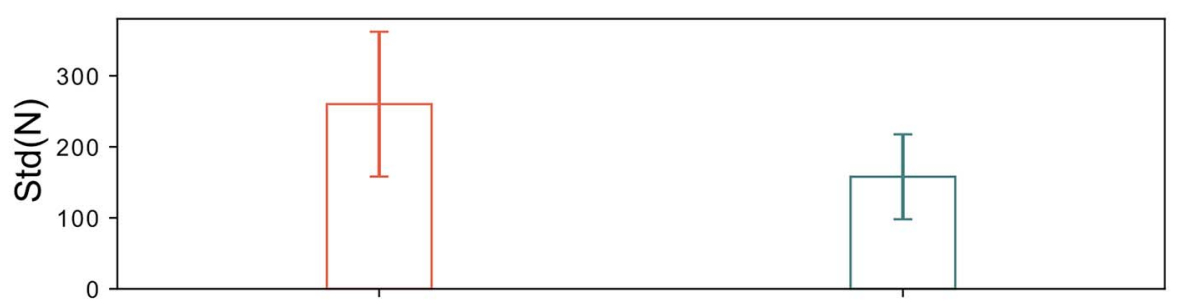

Figure 5. Altered swimming behaviour of adult ncoa3 $-/-$ suggests hearing malfunction. A) Overlapped Trajectories of 1 -year old wt $(n=7)$ and $n c o a 3-/-(n=6)$. The bottom right corner is shaded, where the fish are more likely to stay. B) Average spatial distribution of wt and ncoa3-/-. A brighter colour indicates that the fish are more likely to stay in the respective region. For every trajectory acquired from different fish, the corresponding spatial distribution $\mathrm{P}(\mathrm{N})$ was calculated. From every $\mathrm{P}(\mathrm{N})$, the standard deviation of $\mathrm{N}$ in all the grids is calculated, noted as Std(N). C) Graph of Std(N) values for wt and ncoa3-/-. Error bars represent the standard deviation of $\operatorname{Std}(\mathrm{N})$. Non-parametric, two tailed, t-Test was used $(\mathrm{p}=0.06)$.

bone morphology in affected individuals from the pedigree, it would be interesting to further investigate overall calvarial bone thickness and bone mineral density in the family, as such data are currently unavailable. Moreover, computed tomography is not sensitive enough to detect possible subtle changes at the cellular level that could be contributing to hearing loss as suggested by our functional analysis.

Altered swimming behaviour was previously detected when mutant larvae for several hearing loss associated genes were analysed, such as grhl2b, myo7aa, cdh23, otofa and otofb $(58,59)$. Mutations in the human orthologs are associated with mild to severe hearing loss (60-63). The respective zebrafish mutants have severe abnormalities in the inner ear, otoliths and/or lateral line, and recapitulate abnormalities of those observed in human patients. However, they differ from subtle and progressive changes involved in ncoa3 zebrafish mutants and the family that we described. We did not observe larval behaviour changes in ncoa3-/- (data not shown). But we observed adult behaviour changes that fit with progressive hearing loss. While assessment of hearing loss through adult swimming behaviour in zebrafish is not well explored yet, it has been shown that when adult zebrafish are introduced into a centre of a magnetic field they exhibited altered exploratory behaviour due to vestibular malfunction and independent of lateral line function (31). Therefore, vestibular function can be assessed by exploratory behaviour changes. In a new environment under constant background noise, we would expect that fish carrying hearing disability would display altered behaviour. Ectopic mineral deposition within the ears of adult mutant zebrafish and increased density of otoliths and craniofacial bones are potentially correlated with the altered vestibular function and swimming behaviour found in adult mutants.

Although family size does not allow a definite conclusion about the c.2810C > G variant being causative to hearing loss, our functional results were compatible with the hypothesis of NCOA3 playing a role in hearing, suggesting skeletal homeostasis (cartilage behaviour and bone density) as a strong factor involved in the condition. Our contribution was to attract further attention to NCOA3 as possibly involved in hearing, since many groups are dealing with patient samples revealing hundreds of candidate variants after exome sequencing, without clues to find the causative one. Further functional studies to evaluate the precise effect of the missense variant p.Ser937Cys in NCOA3 function would add value in understanding age-related hearing loss in patients with autosomal dominant pathogenic variants in NCOA3. 


\section{Materials and Methods}

\section{Patients}

A large Brazilian family comprising 5 generations and 15 reported affected individuals with hearing loss was ascertained in our genetic counselling unit (Centro de Pesquisas sobre o Genoma Humano e Células-Tronco-IBUSP) for molecular studies. The transmission of hearing loss in the pedigree is compatible with autosomal dominant inheritance (Figure 1A). For molecular studies, DNA samples from 19 individuals were collected: 7 from affected individuals (III-5, III-8, III-10, IV-6, IV9, IV-21, IV-22), and 12 from unaffected individuals, including spouses (II-4, III-11, IV-5, IV-12, IV-15, IV-17, IV-18, IV-19, IV-20, V-3, V-5 e V-6). Written informed consent was obtained from every participant or the respective guardians. The study was approved by the Ethics Committee from Instituto de Biociências da Universidade de São Paulo.

\section{Audiological evaluation}

Pure tone audiometry, both air (frequencies ranging from 250 to $8000 \mathrm{~Hz}$ ) and bone conduction (frequencies ranging from 500 to $4000 \mathrm{~Hz}$ ) were performed for identification of hearing threshold levels in seven affected individuals (III-5, III-8, III-10, IV-6, IV9, IV-21 and IV-22) and eleven non-affected individuals (III-11, IV-5, IV-12, IV-15, IV-17, IV-18, IV-19, IV-20, V-3, V-5 and V-6). Most of these exams were done at DERDIC (Divisão de Educação e Reabilitação dos Distúrbios da Comunicação, PUCSP), while some were conducted by other institutions prior to this study.

\section{SNP-array and microsatellite markers genotyping}

Genomic DNAs from seven affected individuals (III-5; III-8 III-10; IV-6; IV-9; IV-21; IV-22) were submitted to SNP-Array $(50 \mathrm{~K})$ assays (Affymetrix GeneChip HumanMapping $50 \mathrm{~K}$ Array, Affymetrix), using the manufacturer's reagents (XbaI) and following the GeneChip Mapping $10 \mathrm{~K} 2.0$ Assay Manual. Scanning was performed in a Genechip Scanner 3000 and interpreted with Affymetrix Genotyping Console software (Affymetrix). In addition, twelve polymorphic microsatellite markers mapped to chromosome 20 (ABI Prism Linkage Mapping Sets v2.5) were genotyped in 16 samples (II-4, III-5, III-8, III-10, IV-5, IV-6, IV-9, IV-12, IV-16, IV-17, IV-18, IV-19, IV-20, IV-21, IV-22, $\mathrm{V}-3)$.

\section{LOD score calculations}

Penetrance of hearing loss was estimated according to methods previously described (64). The most likely value of penetrance was $\mathrm{K}=0.6364$. SNP array dataset was previously filtered under quality control filters, using King 2.1.5 program (65) to remove markers with low call rate $(<80 \%)$, besides those monomorphic. The dataset was further pruned to linkage disequilibrium using Plink 1.90 beta program (66) with the indep-pairwise option (window size $10 \mathrm{~kb}$, step size 1,r2 0.5). Multipoint logarithm of odds (LOD) score values were calculated, for each autosome, using Merlin program version 1.1.2 (67) under dominant inheritance model, assuming a rare allele (frequency $=0.001$ ). The LOD score calculations were performed considering penetrance of $\mathrm{K}=0.6364$, but also under the assumption of penetrance $\mathrm{K}=0.8$ and complete penetrance, $\mathrm{K}=1$.

\section{Whole-exome sequencing}

DNA samples from two affected individuals (III-8 and III-10) were submitted to whole-exome sequencing. The library was prepared with Nextera rapid capture kit (Illumina), sequence capture was performed with Illumina Exome enrichment kit ( $62 \mathrm{Mb}$ target size) and sequencing was performed using HiSeq 2500. Fastq files were aligned against reference GRCh37 with Burrows-Wheeler Aligner (BWA) (68), realignment of indel regions, discovery of variants and recalibration of base qualities were performed using GATK software (69) for the production of VCF files; the VCF was annotated by ANNOVAR software (70). Variant frequencies were compared with public variant databases: 1000 Genomes (71), National Heart, Lung, and Blood Institute Exome Sequencing Project (NHLBI-ESP) (72), Genome Aggregation Database (gnomAD) (73) and Online Archive of Brazilian Mutations (ABraOM) (74). Polyphen-2 (75), SIFT (76), Provean (77) and MutationTaster2 (78) were used for in silico damage prediction to the protein. Protein sequence alignment near the best candidate variant was performed by Clustal Omega alignment program (79).

\section{Sanger sequencing}

The DNA regions containing candidate variants filtered after exome sequencing were amplified by PCR. The products were bi-directionally Sanger sequenced with the BigDye Terminator v3.1 Cycle Sequencing Kit (ThermoFisher Scientific) in ABI 3730 DNA Analyzer (Applied Biosystems). NCOA3F-5'GGCTGTACTTACATGGTATAAGAAGG3', NCOA3R- 5'AG GGGAGGGTGGACACTTAC3', DIAPH3F -5'CAAGGGTTTCTGTGCATACC3', DIAPH3R-5'CACTACTCGTTAGTAAATGGAAGGG3', USH1CF -5'GCTGAGAAGACCACCTGCAT3', USH1CR- 5'GAGGAGGAGGAAGTTGGCTG3' were used as primers. Sequences were analysed using Bioedit (Ibis Biosciences).

\section{Multiple alignment of NCOA3 and its orthologous}

Multiple alignment of NCOA3 gene and protein with its orthologous was performed using Clustal Omega provided by European Bioinformatics Institute (EMBL-EBI) (80). For this purpose, the following sequences were used: Homo sapiens (NM_181659.2 and NP_858045.1); Pan troglodytes (XM_016938072.2 and XP_016793561.2); Macaca mulatta (XM_015148801.1 and XP_015004287.1); Bos Taurus (XM_002692493.4 and XP_002692539.1;Mus musculus (NM_008679.3 and NP_032705.2); Rattus norvegicus (XM_006235634.2 and XP_006235696.2); Gallus gallus (XM_004947056.2 and XP_004947113.2); Danio rerio (XM_687846.9 and XP_692938.5) Xenopus tropicalis (XM_018097860.1 and XP_017953349.1).

\section{Mice husbandry}

CBL57/6 mice were obtained from Centro de Pesquisas sobre o Genoma Humano e Células-Tronco (IBUSP) experimentation housing facility. The animals were housed as previously described by Council for International Organizations of Medical Sciences (CIOMS) (81). All experiments with mice were ethically approved by the Internal Review Board on Ethics in Animal Research from the Instituto de Biociências da Universidade de São Paulo (Process Number 16.1.668.41.6).

\section{Cochleae and organ of Corti dissection}

Cochleae and organ of Corti with stria vascularis were harvested from CBL57/6 decapitated mice at 4, 10, 14 and 16 day-old (P4P16) postnatal CBL57/6 mice. After decapitation, the head was bathed in ethanol $70 \%$, followed by longitudinal incision at 
the skull's sagittal line and visualization of the temporal bone, allowing the dissection of the labyrinth. For RNA extraction, the labyrinths were transferred to a Petri dish with RNAlater ${ }^{\circledR}$ (Sigma Aldrich). Cochlea and organ of Corti with stria vascularis were then surgically harvested with micro tweezers (Dumont \#5 e \#54, Koch Electron Microscopy) under trinocular stereomicroscope (Discovery V12, Carl Zeiss). For immunofluorescence assays, cochleae were isolated from labyrinths kept in phosphate buffered saline (PBS), using micro tweezers (Dumont \#5 e \#54, Koch Electron Microscopy) under trinocular stereomicroscope (Discovery V12).

\section{RT-PCR}

Total RNA extraction was performed with a pool of 12 cochleae or 12 organs of Corti with stria vascularis from P4, P10 and P16 mice, as well as with gastrocnemius sample of P180 mice. Total RNA was extracted with RNeasy Microarray Tissue Mini Kit (QIAGEN). Synthesis of cDNA was performed with RNeasy Microarray Tissue Mini Kit (QIAGEN), using $1 \mu \mathrm{g}$ of total RNA. Primers used for this experiment were: Ncoa3F-5'CGTTTCTCCTTGGCTGATGG3', Ncoa3R-5'CGGGATTTGGGTTTGGTCTG3', ActbF-5'GGCTGTATTCCCCTCCATCG3', ActbR-5'CCAGTTGGTAACAATGCCATGT3', B2mF5'TCGCGGTCGCTTCAGTCGTC3', B2mR- 5'TTCTCCGGTGGGTGGCGTGA3'. Control experiments concomitantly performed were negative control of cDNA synthesis (using water instead of extracted RNA), negative control of RT-PCR (using water instead of CDNA), and positive control (using cDNA synthetized from gastrocnemius RNA). Housekeeping genes used as reference for this experiment were $A c t b$ and $B 2 m$.

\section{Immunofluorescence assays}

Cochleae preparation and immunofluorescence assays were performed as described by (82). Cochleae were perfused locally and fixed in $4 \%$ paraformaldehyde (PFA) at $4^{\circ} \mathrm{C}$ overnight $(\mathrm{o} / \mathrm{n})$. P10 and P14 passed through decalcification with 10\% EDTA and $1 \%$ PFA at $4^{\circ} \mathrm{C}$ for 4 days. All tissues were washed with 1X PBS, submitted to serial dilutions of sucrose solution and Jung Tissue Freezing Medium (Leica Microsystems), frozen and transversely cryosectioned in $12 \mu \mathrm{m}$. Slides were stored at $-80^{\circ} \mathrm{C}$ until use. For immunofluorescence assays, histological slides were simultaneously permeabilized and blocked with $0.3 \%$ triton $\mathrm{X}-100$ and $4 \%$ bovine serum albumin (BSA) solution, followed by incubation in solution containing 1:50 polyclonal anti-NCOA3 antibody (anti-SCR3 antibody-ChIP Grade, Rabbit Polyclonal, ab2831, Abcam Inc.) diluted in $0.1 \%$ triton X-100 and $4 \%$ BSA, at $4^{\circ} \mathrm{C} \mathrm{o} / \mathrm{n}$. Subsequently, the slides were incubated in solution containing 1:500 anti-rabbit AlexaFluor-568 diluted in $0.1 \%$ triton $\mathrm{X}-100,1 \% \mathrm{BSA}$, at for $2 \mathrm{~h}$ at room temperature. After rinse in PBS, the slides were then mounted with Prolong Gold Antifade Reagent (Invitrogen) with DAPI for nuclei staining. Images were taken confocal microscope either LSM 780 (Carl Zeiss) or LSM880 (Carl Zeiss), using Zen software (Carl Zeiss).

\section{Zebrafish husbandry and lines}

Zebrafish were housed as previously described (83). Animal experiments were ethically approved by the Animal Welfare and Ethical Review Body (AWERB) at the University of Bristol and performed under a UK Home Office project and by the Internal Review Board on Ethics in Animal Research from the Instituto de Biociências da Universidade de São Paulo (Process Number 16.1.668.41.6). Transgenic lines used have been previously described: TgBAC(Col2a1a:mCherry) $)^{\text {hu5910 }}$ (84) and $\mathrm{Tg}$ (notch:egfp) (85).

\section{Whole-mount in situ hybridization in zebrafish}

Whole-mount in situ hybridizations on zebrafish samples were performed as described by (86). ncoa3 in situ probe was synthesised in vitro from a PCR product (880 bp amplified from exon11) using a T7 RNA Polymerase for transcription (ThermoFisher Scientific) and DIG-labelling Mix (Roche)followed by purification with SigmaSpin ${ }^{\text {TM }}$ Post-Reaction Clean-Up Columns (Sigma Aldrich). The following primers were used for the PCR: ncoa3F (5'GAATACCTTCTCTAGCAGCTCATTG3') and ncoa3-R (5'taatacgactcactatagggagCTTATTGAGGAGGTAGTGAAGGAGG3').

\section{Generation of zebrafish ncoa3-/-}

ncoa3 mutants were generated by CRISPR/Cas9 system as previously described (87). A gRNA was designed to target ncoa3: TGGGGTCTCCGCGGATACGAGGG(PAM) (chr11:1851605918516081). Once synthesised, it was incubated with GeneArt Platinum Cas9 nuclease (Invitrogen) prior to injections into 1 cell stage zebrafish embryos. DNA was extracted from 20 individual larvae at 2 days post fertilization (dpf), followed by PCR amplification (ncoa3CRISPR F: FAM-ATGAATGAGCAAGGCCACAT; ncoa3CRIPSR R: GGACTTGCTCCCATTTTAGG) and subjected to fragment length analysis (ABI 3500) to test gRNA efficiency ( $90 \%$ efficiency rate detected). G0s were outcrossed to generate G1s which were submitted to Sanger sequencing. The mutant line ncoa ${ }^{\text {bi456 }}$ carries a $5 \mathrm{bp}$ deletion, leading to a premature stop codon predicted to undergo mRNA nonsense mediated decay.

\section{Microscopy}

Samples were mounted in $1 \%$ low melting point (LMP) agarose (Invitrogen) and imaged with a Leica SP5II confocal microscopy (Leica LAS software) using 10x PL APO CS (dry), 20x immersion lens (phalloidin) or 40x PL APO CS (oil) lenses (cristae imaging). LasX (Leica) and Amira 6.0 (FEI) was used for 2D and 3D rendering, image analysis and picture acquisition.

\section{D perspective measurements of the otic vesicle}

Two distinct 3D perspective measurements (sagittal/ $\mathrm{x}$ axis and coronal/y axis) were taken of the major axis of the otic vesicle at $5 \mathrm{dpf}$ from confocal images using Amira 6.0. GraphPad (Prism) was used for statistical analysis. t-Tests (non-parametric, MannWhitney $U$ test, $p<0.05$ ) were performed ( $n=7$ for each group).

\section{Phalloidin staining}

Larvae (5dpf) were fixed in $4 \% \mathrm{PFA}$ at $4^{\circ} \mathrm{C}$ o/n, washed in PBS 3 x 5 minutes and incubated in AlexaFluor 555 conjugated phalloidin (1:20 in PBS) o/n at $4^{\circ} \mathrm{C}$ (protocol adapted from (88)). Samples were then washed in PBS $3 \times 15$ minutes, mounted laterally in $0.5 \%$ LMP agarose and imaged on a confocal microscopy.

\section{Micro-computerised tomography $(\mu \mathrm{CT})$ and bone mineral density calculation}

Adult fish (1 year old) were fixed in 4\% PFA for 1 week followed by sequential dehydration to $70 \%$ ethanol. Fish heads were scanned using an XT H 225ST $\mu$ CT scanner (Nikon) with voxel size of $20 \mu \mathrm{m}$ and $5 \mu \mathrm{m}$ for detailed geometric analysis, using an x-ray source of $130 \mathrm{kV}, 53 \mu \mathrm{A}$ and without additional filters. Images 
were reconstructed using CT Pro 3D software (Nikon). Amira 6.0 was used for image analysis and to generate 3D volume and surface renders. Lagenal otoliths were segmented from $\mu \mathrm{CT}$ images ( $20 \mu \mathrm{m}$ resolution) and bone density was quantified by sampling a region 20 slices thick at the centre of the otoliths. Greyscale values were calibrated against phantom blocks with calibrated densities.

\section{Adult swimming behaviour analysis}

Swimming behaviour was assessed by recording 2D movement (from above) in a rectangular tank. Individual fish (1 year old, wild type (wt) $n=7$ and ncoa3-/ $-\mathrm{n}=6$ ) were transferred to a tank $(35 \mathrm{~cm} \times 40 \mathrm{~cm})$ containing a shaded corner $(10 \mathrm{~cm} \mathrm{x}$ $10 \mathrm{~cm}$ ) and a total of $8 \mathrm{~L}$ of water. The tank was placed in an environment of constant background noise $(\sim 80 \mathrm{~dB})$ and recorded with a digital camera (Balser acA2040-120 $\mu \mathrm{m}$ ) at a frame rate of 15 frames/s, for 10 minutes (9000 frames). The 2D positions in different frames were calculated by a custom Python script (89). Trajectories were obtained by applying a fourframe best estimate algorithm (90) to the positions, and further refined following the approach described in (91). For each fish, we calculated its normalised 2D spatial distribution $\mathrm{P}(\mathrm{N})$ where $\mathrm{N}$ is the number of times the fish stays in a grid, whose size is 100 pixels by 100 pixels. We then calculated the standard deviation of $\mathrm{N}$ in all grids as a proxy to the spatial distribution heterogeneity, noted as $\operatorname{Std}(\mathrm{N})$. The difference in the behaviours between the wt fish and the mutant fish is then characterised by $\operatorname{Std}(\mathrm{N})$ values of each individual. Assuming the spatial heterogeneity of the wt fish and the mutant fish follow the normal distributions with different variances, we used student $t$ test to calculate the probability of their average values being the same $(p<0.05$ statistically significant).

\section{Supplementary data}

Supplementary data mentioned in the text are available to subscribers in HMG online.

\section{Author contributions}

RSS, VLGD, FSN, BCN, EL, AK, YY and EK performed experiments. RSS, VLGD, LUA, ACB, JO, EL, AK, YY, RCMN and EK analysed data. The project was designed by RCMN (gene identification) and EK (functional analysis). All authors contributed to drafting the manuscript.

\section{Acknowledgements}

EK and CH were funded by Versus Arthritis (21937, 21211). AK was funded by BBSRC SWBio-DTP studentship and EL by a Wellcome Trust Dynamic Molecular Cell Biology PhD studentship. This work was supported by Fundação de Amparo à Pesquisa do Estado de São Paulo (FAPESP_CEPID Human Genome and Stem-Cell Research Center 2013/08028-1), Coordenação de Aperfeiçoamento de Pessoal de Nível Superior-CAPES and Conselho Nacional de Desenvolvimento Científico e Tecnológico (CNPq, grant 133182/2015-0). The authors are indebted to all professionals of Divisão de Educação e Reabilitação dos Distúrbios da Comunicação (DERDIC) da Pontifícia Universidade Católica de São Paulo, São Paulo (PUC-SP), in special to Márcia Zucheratto, for audiological evaluations. We thank Dr. Maria Rita PassosBueno for support on establishing the zebrafish laboratory at Instituto de Biociências da Universidade da São Paulo (IBUSP),
Dr. Marília O. Scliar for bioinformatics assistance, Dr. Chao Yun Irene Yan for assistance with acquisition of zebrafish in situs images, Waldir Caldeira and Mario Cruz for helping with mice sectioning and image acquisition. We are greatly indebted to Ms Vinícius Magalhães Borges for assistance in LOD score calculations. We also thank Ms André S. Bueno for assistance and Drs. Erika Freitas and Carla Rosenberg for Array-CGH.

Conflicts of interest. We declare no competing interests.

\section{Abbreviations}

Animal Welfare and Ethical Review Body AWERB; Autosomal dominant non-syndromic hearing loss ADNSHL; Bovine serum albumin BSA; Council for International Organizations of Medical Sciences CIOMS; Clustered regularly interspaced short palindromic repeats CRISPR; CRISPR associated protein 9 Cas9; Days post fertilization dpf; Ear, nose and throat ENT; European Bioinformatics Institute EMBL-EBI; Genome Aggregation Database gnomAD; Multipoint logarithm of odds LOD; National Heart, Lung, and Blood Institute Exome Sequencing Project NHLBI-ESP; Online Archive of Brazilian Mutations ABraOM; Paraformaldehyde PFA; Postnatal Day P; Weeks post fertilization Wpf.

\section{Funding}

Wellcome Trust grant number 108907/Z/15/Z.

\section{References}

1. WHO| World Health Organization. WHO|World Health Organization http://www.who.int (accessed Aug 23, 2018).

2. Shearer, A.E., Hildebrand, M.S. and Smith, R.J. (1993) In Adam, M.P., Ardinger, H.H., Pagon, R.A. et al. (eds), Hereditary Hearing Loss and Deafness Overview. GeneReviews ${ }^{\circledR}$, University of Washington, Seattle, Seattle (WA).

3. Keats, B.J.B. and Berlin, C.I. (1999) Genomics and hearing impairment. Genome Res., 9, 7-16.

4. Vona, B., Nanda, I., Hofrichter, M.A.H., Shehata-Dieler, W. and Haaf, T. (2015) Non-syndromic hearing loss gene identification: a brief history and glimpse into the future. Mol. Cell. Probes, 29, 260-270.

5. Brownstein, Z., Friedman, L.M., Shahin, H., Oron-Karni, V., Kol, N., Rayyan, A.A., Parzefall, T., Lev, D., Shalev, S., Frydman, M. et al. (2011) Targeted genomic capture and massively parallel sequencing to identify genes for hereditary hearing loss in middle eastern families. Genome Biol., 12, R89.

6. Diaz-Horta, O., Duman, D., Ii, J.F., Sirmac1, A., Gonzalez, M., Mahdieh, N., Fotouhi, N., Bonyadi, M., Cengiz, F.B., Menendez, I. et al. (2012) Whole-exome sequencing efficiently detects rare mutations in autosomal recessive Nonsyndromic hearing loss. PLoS One, 7, e50628.

7. Wu, C.-C., Lin, Y.-H., Lu, Y.-C., Chen, P.-J., Yang, W.-S., Hsu, C.-J. and Chen, P.-L. (2013) Application of massively parallel sequencing to genetic diagnosis in multiplex families with idiopathic sensorineural hearing impairment. PLoS One, 8, e57369.

8. Pandya, A. (2016) Genetic hearing loss: the journey of discovery to destination - how close are we to therapy? Mol. Genet. Genomic Med., 4, 583-587.

9. Welcome to the Hereditary Hearing Loss Homepage | Hereditary Hearing Loss Homepage. Welcome to the hereditary hearing loss homepage | hereditary hearing loss homepage https://hereditaryhearingloss.org/ (accessed May 3, 2020). 
10. Zhao, H.-B., Kikuchi, T., Ngezahayo, A. and White, T.W. (2006) Gap junctions and cochlear homeostasis. J. Membr. Biol., 209, 177.

11. Lynch, E.D., Lee, M.K., Morrow, J.E., Welcsh, P.L., León, P.E. and King, M.-C. (1997) Nonsyndromic deafness DFNA1 associated with mutation of a human homolog of the drosophila gene diaphanous. Science, 278, 1315-1318.

12. Belyantseva, I.A., Boger, E.T., Naz, S., Frolenkov, G.I., Sellers, J.R., Ahmed, Z.M., Griffith, A.J. and Friedman, T.B. (2005) Myosin-XVa is required for tip localization of whirlin and differential elongation of hair-cell stereocilia. Nat. Cell Biol., 7, 148-156.

13. Vahava, O., Morell, R., Lynch, E.D., Weiss, S., Kagan, M.E., Ahituv, N., Morrow, J.E., Lee, M.K., Skvorak, A.B., Morton, C.C. et al. (1998) Mutation in transcription factor POU4F3 associated with inherited progressive hearing loss in humans. Science, 279, 1950-1954.

14. Collin, R.W.J., Kalay, E., Tariq, M., Peters, T., van der Zwaag, B., Venselaar, H., Oostrik, J., Lee, K., Ahmed, Z.M., Çaylan, R. et al. (2008) Mutations of ESRRB encoding Estrogen-related receptor Beta cause autosomal-recessive nonsyndromic hearing impairment DFNB35. Am. J. Hum. Genet., 82, 125-138.

15. Hilgert, N., Smith, R.J.H. and Van Camp, G. (2009) Forty-six genes causing nonsyndromic hearing impairment: which ones should be analyzed in DNA diagnostics? Mutat. Res. Mutat. Res., 681, 189-196.

16. Gariballa, N., Ben-Mahmoud, A., Komara, M., Al-Shamsi, A.M., John, A., Ali, B.R. and Al-Gazali, L. (2017) A novel aberrant splice site mutation in COL27A1 is responsible for Steel syndrome and extension of the phenotype to include hearing loss. Am. J. Med. Genet. A, 173, 1257-1263.

17. Booth, K.T., Askew, J.W., Talebizadeh, Z., Huygen, P.L.M., Eudy, J., Kenyon, J., Hoover, D., Hildebrand, M.S., Smith, K.R., Bahlo, M. et al. (2019) Splice-altering variant in COL11A1 as a cause of nonsyndromic hearing loss DFNA37. Genet. Med. Off. J. Am. Coll. Med. Genet., 21, 948-954.

18. Nixon, T.R.W., Alexander, P., Richards, A., McNinch, A., Bearcroft, P.W.P., Cobben, J. and Snead, M.P. (2019) Homozygous type IX collagen variants (COL9A1, COL9A2, and COL9A3) causing recessive Stickler syndrome-expanding the phenotype. Am. J. Med. Genet. A, 179, 1498-1506.

19. Xu, J., Liao, L., Ning, G., Yoshida-Komiya, H., Deng, C. and O'Malley, B.W. (2000) The steroid receptor coactivator SRC3 (p/CIP/RAC3/AIB1/ACTR/TRAM-1) is required for normal growth, puberty, female reproductive function, and mammary gland development. Proc. Natl. Acad. Sci. U. S. A., 97, 6379-6384.

20. Louet, J.-F., Coste, A., Amazit, L., Tannour-Louet, M., Wu, R.C., Tsai, S.Y., Tsai, M.-J., Auwerx, J. and O'Malley, B.W. (2006) Oncogenic steroid receptor coactivator-3 is a key regulator of the white adipogenic program. Proc. Natl. Acad. Sci. U. S. A., 103, 17868-17873.

21. York, B., Reineke, E.L., Sagen, J.V., Nikolai, B.C., Zhou, S., Louet, J.-F., Chopra, A.R., Chen, X., Reed, G., Noebels, J. et al. (2012) Ablation of steroid receptor Coactivator-3 resembles the human CACT metabolic myopathy. Cell Metab., 15, 752-763.

22. Scheffer, D.I., Shen, J., Corey, D.P. and Chen, Z.-Y. (2015) Gene expression by mouse inner ear hair cells during development. J. Neurosci., 35, 6366-6380.

23. Liu, H., Pecka, J.L., Zhang, Q., Soukup, G.A., Beisel, K.W. and He, D.Z.Z. (2014) Characterization of Transcriptomes of Cochlear inner and outer hair cells. J. Neurosci., 34, 11085-11095.
24. Zhang, B., Li, Z., Wang, W., Guo, J., Kang, S., Liu, S., Li, H., Wang, D. and Qi, X. (2018) NCOA3 loss disrupts molecular signature of chondrocytes and promotes posttraumatic osteoarthritis progression. Cell. Physiol. Biochem. Int. J. Exp. Cell. Physiol. Biochem. Pharmacol., 49, 2396-2413.

25. Gee, F., Rushton, M.D., Loughlin, J. and Reynard, L.N. (2015) Correlation of the osteoarthritis susceptibility variants that map to chromosome 20q13 with an expression quantitative trait locus operating on NCOA3 and with functional variation at the polymorphism rs116855380. Arthritis Rheumatol. Hoboken NJ, 67, 2923-2932.

26. Evangelou, E., Kerkhof, H.J., Styrkarsdottir, U., Ntzani, E.E., Bos, S.D., Esko, T., Evans, D.S., Metrustry, S., Panoutsopoulou, K., Ramos, Y.F.M. et al. (2014) A meta-analysis of genomewide association studies identifies novel variants associated with osteoarthritis of the hip. Ann. Rheum. Dis., 73, 2130-2136.

27. Sheu, Y.-T., Zmuda, J.M., Cauley, J.A., Moffett, S.P., Rosen, C.J., Ishwad, C. and Ferrell, R.E. (2006) Nuclear receptor Coactivator-3 alleles are associated with serum bioavailable testosterone, insulin-like growth Factor-1, and vertebral bone mass in men. J. Clin. Endocrinol. Metab., 91, 307-312.

28. Ao, X., Nie, P., Wu, B., Xu, W., Zhang, T., Wang, S., Chang, H. and Zou, Z. (2016) Decreased expression of microRNA17 and microRNA-20b promotes breast cancer resistance to taxol therapy by upregulation of NCOA3. Cell Death Dis., 7, e2463-e2463.

29. Lundberg, Y.W., Xu, Y., Thiessen, K.D. and Kramer, K.L. (2015) Mechanisms of otoconia and otolith development. Dev. Dyn., 244, 239-253.

30. Stooke-Vaughan, G.A., Obholzer, N.D., Baxendale, S., Megason, S.G. and Whitfield, T.T. (2015) Otolith tethering in the zebrafish otic vesicle requires Otogelin and $\alpha$-Tectorin. Development, 142, 1137-1145.

31. Ward, B.K., Tan, G.X.-J., Roberts, D.C., Santina, C.C.D., Zee, D.S. and Carey, J.P. (2014) Strong static magnetic fields elicit swimming Behaviors consistent with direct vestibular stimulation in adult Zebrafish. PLoS One, 9, e92109.

32. Diaz-Horta, O., Abad, C., Sennaroglu, L., Foster, J., DeSmidt, A., Bademci, G., Tokgoz-Yilmaz, S., Duman, D., Cengiz, F.B., Grati, M. et al. (2016) ROR1 is essential for proper innervation of auditory hair cells and hearing in humans and mice. Proc. Natl. Acad. Sci., 113, 5993-5998.

33. Chen, M., Wang, Q., Zhu, G.-H., Hu, P., Zhou, Y., Wang, T., Lai, R.-S., Xiao, Z.-A. and Xie, D.-H. (2016) Progressive hearing loss and degeneration of hair cell stereocilia in taperin gene knockout mice. Biochem. Biophys. Res. Commun., 479, 703-707.

34. Kwon, H.-J. (2016) Vitamin D receptor deficiency impairs inner ear development in zebrafish. Biochem. Biophys. Res. Commun., 478, 994-998.

35. Borck, G., Rehman, A.U., Lee, K., Pogoda, H.-M., Kakar, N., von Ameln, S., Grillet, N., Hildebrand, M.S., Ahmed, Z.M., Nürnberg, G. et al. (2011) Loss-of-function mutations of ILDR1 cause autosomal-recessive hearing impairment DFNB42. Am. J. Hum. Genet., 88, 127-137.

36. Heeringa, S.F., Chernin, G., Chaki, M., Zhou, W., Sloan, A.J., Ji, Z., Xie, L.X., Salviati, L., Hurd, T.W., Vega-Warner, V. et al. (2011) COQ6 mutations in human patients produce nephrotic syndrome with sensorineural deafness. J. Clin. Invest., 121, 2013-2024.

37. von Ameln, S., Wang, G., Boulouiz, R., Rutherford, M.A., Smith, G.M., Li, Y., Pogoda, H.-M., Nürnberg, G., Stiller, B., Volk, A.E. et al. (2012) A mutation in PNPT1, encoding mitochondrial-RNA-import protein PNPase, causes hereditary hearing loss. Am. J. Hum. Genet., 91, 919-927. 
38. Azaiez, H., Decker, A.R., Booth, K.T., Simpson, A.C., Shearer, A.E., Huygen, P.L.M., Bu, F., Hildebrand, M.S., Ranum, P.T., Shibata, S.B. et al. (2015) HOMER2, a Stereociliary scaffolding protein, is essential for normal hearing in humans and mice. PLoS Genet., 11, e1005137.

39. Li, J., Zhao, X., Xin, Q., Shan, S., Jiang, B., Jin, Y., Yuan, H., Dai, P., Xiao, R., Zhang, Q. et al. (2015) Whole-exome sequencing identifies a variant in TMEM132E causing autosomalrecessive nonsyndromic hearing loss DFNB99. Hum. Mutat., 36, 98-105.

40. Dasgupta, S., Lonard, D.M. and O'Malley, B.W. (2014) Nuclear receptor Coactivators: master regulators of human health and disease. Annu. Rev. Med., 65, 279-292.

41. Yuan, Y., Liao, L., Tulis, D.A. and Xu, J. (2002) Steroid receptor Coactivator-3 is required for inhibition of neointima formation by estrogen. Circulation, 105, 2653-2659.

42. Xu, J., Shao, Z., Glass, K., Bauer, D.E., Pinello, L., Van Handel, B., Hou, S., Stamatoyannopoulos, J.A., Mikkola, H.K.A., Yuan, G.-C. et al. (2012) Combinatorial assembly of developmental stage-specific enhancers controls gene expression programs during human erythropoiesis. Dev. Cell, 23, 796-811.

43. Han, S.J., DeMayo, F.J., Xu, J., Tsai, S.Y., Tsai, M.-J. and O'Malley, B.W. (2006) Steroid receptor Coactivator (SRC)-1 and SRC-3 differentially modulate tissue-specific activation functions of the progesterone receptor. Mol. Endocrinol., 20, 45-55.

44. Wang, Z., Shah, O.J. and Hunter, T. (2012) The transcriptional Coactivators $\mathrm{p} / \mathrm{CIP}$ and SRC-1 control insulin resistance through IRS1 in obesity models. PLoS One, 7, e36961.

45. Wu, Z., Yang, M., Liu, H., Guo, H., Wang, Y., Cheng, H. and Chen, L. (2012) Role of nuclear receptor Coactivator 3 (Ncoa3) in Pluripotency maintenance. J. Biol. Chem., 287, 38295-38304.

46. York, B., Sagen, J.V., Tsimelzon, A., Louet, J.-F., Chopra, A.R., Reineke, E.L., Zhou, S., Stevens, R.D., Wenner, B.R., Ilkayeva, O. et al. (2013) Research resource: tissue- and pathway-specific Metabolomic profiles of the steroid receptor Coactivator (SRC) family. Mol. Endocrinol., 27, 366-380.

47. Coste, A., Louet, J.-F., Lagouge, M., Lerin, C., Antal, M.C., Meziane, H., Schoonjans, K., Puigserver, P., O’Malley, B.W. and Auwerx, J. (2008) The genetic ablation of SRC-3 protects against obesity and improves insulin sensitivity by reducing the acetylation of PGC- $1 \alpha$. Proc. Natl. Acad. Sci., 105, 17187-17192.

48. Wang, Z., Rose, D.W., Hermanson, O., Liu, F., Herman, T., Wu, W., Szeto, D., Gleiberman, A., Krones, A., Pratt, K. et al. (2000) Regulation of somatic growth by the p160 coactivator p/CIP. Proc. Natl. Acad. Sci., 97, 13549-13554.

49. Nicolson, T. (2005) The genetics of hearing and balance in Zebrafish. Annu. Rev. Genet., 39, 9-22.

50. Romero-Carvajal, A., Navajas Acedo, J., Jiang, L., KozlovskajaGumbrienè, A., Alexander, R., Li, H. and Piotrowski, T. (2015) Regeneration of sensory hair cells requires localized interactions between the Notch and Wnt pathways. Dev. Cell, 34, 267-282.

51. Haddon, C., Jiang, Y.J., Smithers, L. and Lewis, J. (1998) DeltaNotch signalling and the patterning of sensory cell differentiation in the zebrafish ear: evidence from the mind bomb mutant. Development, 125, 4637-4644.

52. Itoh, M. and Chitnis, A.B. (2001) Expression of proneural and neurogenic genes in the zebrafish lateral line primordium correlates with selection of hair cell fate in neuromasts. Mech. Dev., 102, 263-266.

53. Andermann, P., Ungos, J. and Raible, D.W. (2002) Neurogenin1 defines Zebrafish cranial sensory ganglia precursors. Dev. Biol., 251, 45-58.
54. Zhang, B., Li, Z., Wang, W., Guo, J., Kang, S., Liu, S., Li, H., Wang, D. and Qi, X. (2018) NCOA3 loss disrupts molecular signature of chondrocytes and promotes posttraumatic osteoarthritis progression. Cell. Physiol. Biochem., 49, 2396-2413.

55. Aşık, M.D., Gürsoy, S., Akkaya, M., Kozacı, L.D., Doğan, M. and Bozkurt, M. (2019) Microarray analysis of cartilage: comparison between damaged and non-weight-bearing healthy cartilage. Connect. Tissue Res., 0, 1-9.

56. Monsell, E.M. (2004) The mechanism of hearing loss in Paget's disease of bone. Laryngoscope, 114, 598-606.

57. Gregson, C.L., Hardcastle, S.A., Cooper, C. and Tobias, J.H. (2013) Friend or foe: high bone mineral density on routine bone density scanning, a review of causes and management. Rheumatol. Oxf. Engl., 52, 968-985.

58. Han, Y., Mu, Y., Li, X., Xu, P., Tong, J., Liu, Z., Ma, T., Zeng, G., Yang, S., Du, J. et al. (2011) Grhl2 deficiency impairs otic development and hearing ability in a zebrafish model of the progressive dominant hearing loss DFNA28. Hum. Mol. Genet., 20, 3213-3226.

59. Vona, B., Doll, J., Hofrichter, M.A.H., Haaf, T. and Varshney, G.K. (2020) Small fish, big prospects: using zebrafish to unravel the mechanisms of hereditary hearing loss. Hear. Res., 107906.

60. Iwasa, Y., Nishio, S., Yoshimura, H., Kanda, Y., Kumakawa, K., Abe, S., Naito, Y., Nagai, K. and Usami, S. (2013) OTOF mutation screening in Japanese severe to profound recessive hearing loss patients. BMC Med. Genet., 14, 95.

61. Wagatsuma, M., Kitoh, R., Suzuki, H., Fukuoka, H., Takumi, Y. and Usami, S. (2007) Distribution and frequencies of CDH23 mutations in Japanese patients with non-syndromic hearing loss. Clin. Genet., 72, 339-344.

62. Ahmed, Z.M., Riazuddin, S., Riazuddin, S. and Wilcox, E.R. (2003) The molecular genetics of Usher syndrome. Clin. Genet., 63, 431-444.

63. Vona, B., Nanda, I., Neuner, C., Müller, T. and Haaf, T. (2013) Confirmation of GRHL2 as the gene for the DFNA28 locus. Am. J. Med. Genet. A, 161, 2060-2065.

64. Rogatko, A., Pereira, C.A. and Frota-Pessoa, O. (1986) A Bayesian method for the estimation of penetrance: application to mandibulofacial and frontonasal dysostoses. Am. J. Med. Genet., 24, 231-246.

65. Manichaikul, A., Mychaleckyj, J.C., Rich, S.S., Daly, K., Sale, M. and Chen, W.-M. (2010) Robust relationship inference in genome-wide association studies. Bioinformatics, 26, 2867-2873.

66. Chang, C.C., Chow, C.C., Tellier, L.C., Vattikuti, S., Purcell, S.M. and Lee, J.J. (2015) Second-generation PLINK: rising to the challenge of larger and richer datasets. Gigascience, 4.

67. Abecasis, G.R., Cherny, S.S., Cookson, W.O. and Cardon, L.R. (2002) Merlin-rapid analysis of dense genetic maps using sparse gene flow trees. Nat. Genet., 30, 97-101.

68. Li, H. and Durbin, R. (2009) Fast and accurate short read alignment with burrows-wheeler transform. Bioinformatics, 25, 1754-1760.

69. McKenna, A., Hanna, M., Banks, E., Sivachenko, A., Cibulskis, K., Kernytsky, A., Garimella, K., Altshuler, D., Gabriel, S., Daly, M. et al. (2010) The genome analysis toolkit: a MapReduce framework for analyzing next-generation DNA sequencing data. Genome Res., 20, 1297-1303.

70. Wang, K., Li, M. and Hakonarson, H. (2010) ANNOVAR: functional annotation of genetic variants from high-throughput sequencing data. Nucleic Acids Res., 38, e164-e164.

71. 1000 Genomes | A Deep Catalog of Human Genetic Variation. 1000 genomes | a deep Catalog of human genetic 
variation. https://www.internationalgenome.org/ (accessed Aug 16, 2019).

72. Exome Variant Server. Exome variant server https://evs.gs. washington.edu/EVS/ (accessed Aug 16, 2019).

73. gnomAD. gnomAD https://gnomad.broadinstitute.org/ (accessed Aug 16, 2018).

74. ABraOM: Brazilian genomic variants. ABraOM: Brazilian genomic variants http://abraom.ib.usp.br/ (accessed Aug 16, 2018).

75. Adzhubei, I.A., Schmidt, S., Peshkin, L., Ramensky, V.E., Gerasimova, A., Bork, P., Kondrashov, A.S. and Sunyaev, S.R. (2010) A method and server for predicting damaging missense mutations. Nat. Methods, 7, 248-249.

76. Ng, P.C. and Henikoff, S. (2006) Predicting the effects of amino acid substitutions on protein function. Annu. Rev. Genomics Hum. Genet., 7, 61-80.

77. Choi, Y., Sims, G.E., Murphy, S., Miller, J.R. and Chan, A.P. (2012) Predicting the functional effect of amino acid substitutions and Indels. PLoS One, 7, e46688.

78. Schwarz, J.M., Cooper, D.N., Schuelke, M. and Seelow, D. (2014) MutationTaster2: mutation prediction for the deepsequencing age. Nat. Methods, 11, 361-362.

79. Clustal omega < multiple sequence alignment < EMBL-EBI. Clustal omega $<$ multiple sequence alignment $<$ EMBL-EBI https://www.ebi.ac.uk/Tools/msa/clustalo/ (accessed Aug 16, 2019).

80. Madeira, F., Park, Y.M., Lee, J., Buso, N., Gur, T., Madhusoodanan, N., Basutkar, P., Tivey, A.R.N., Porter, S.C., Finn, R.D. et al. (2019) The EMBL-EBI search and sequence analysis tools APIs in 2019. Nucleic Acids Res., 47, W636-W641.

81. Research, N. R. C. (US) I. for L. A. (2004) International Guiding Principles for Biomedical Research Involving Animals (1985) International Guiding Principles for Biomedical Research Involving Animals (1985). National Academies Press (US), (2004).
82. Smeti, I., Watabe, I., Savary, E., Fontbonne, A. and Zine, A. (2014) HMGA2, the architectural transcription factor high mobility group, is expressed in the developing and mature mouse cochlea. PLoS One, 9, e88757.

83. Aleström, P., D’Angelo, L., Midtlyng, P.J., Schorderet, D.F., Schulte-Merker, S., Sohm, F. and Warner, S. (2019) Zebrafish: housing and husbandry recommendations. Lab. Anim., 0023677219869037.

84. Hammond, C.L. and Schulte-Merker, S. (2009) Two populations of endochondral osteoblasts with differential sensitivity to hedgehog signalling. Dev. Camb. Engl., 136, 3991-4000.

85. Parsons, M.J., Pisharath, H., Yusuff, S., Moore, J.C., Siekmann, A.F., Lawson, N. and Leach, S.D. (2009) Notch-responsive cells initiate the secondary transition in larval zebrafish pancreas. Mech. Dev., 126, 898-912.

86. Thisse, C. and Thisse, B. (2008) High-resolution in situ hybridization to whole-mount zebrafish embryos. Nat. Protoc., 3, 59-69.

87. Brunt, L.H., Begg, K., Kague, E., Cross, S. and Hammond, C.L. (2017) Wnt signalling controls the response to mechanical loading during zebrafish joint development. Development, 144, 2798-2809.

88. Goody, M.F., Kelly, M.W., Reynolds, C.J., Khalil, A., Crawford, B.D. and Henry, C.A. (2012) NAD+ biosynthesis ameliorates a Zebrafish model of muscular dystrophy. PLoS Biol., 10.

89. Yushi Yang (2020) yangyushi/FishPy: First release to get a DOI. yangyushi/FishPy: First release to get a DOI; Zenodo, (2020)

90. Ouellette, N.T., Xu, H. and Bodenschatz, E. (2006) A quantitative study of three-dimensional Lagrangian particle tracking algorithms. Exp. Fluids, 40, 301-313.

91. Xu, H. (2008) Tracking Lagrangian trajectories in positionvelocity space. Meas. Sci. Technol., 19, 075105. 